症例

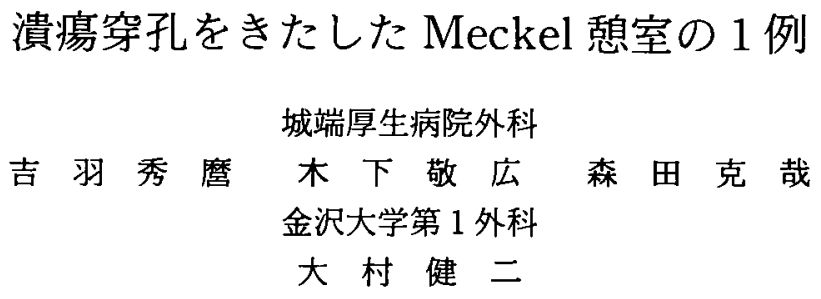

症例は 12 歳，男性. 筫血にて入院・加療を受けた既往がある. 今回，下腹部痛を訴え て当科に入院となった，血液生化学検查にて，鉄欠乏性筫血を認めた．入院後，下腹部 痛の增強に加えて腹膜刺激症状が出現したため, 急性虫垂炎の診断にて開腹した. 腹腔 内には淡血性の腹水が貯留していた. 回盲弁より約 $90 \mathrm{~cm}$ 口側の回腸に, 穿孔した大きさ $6 \mathrm{~cm} \times 3 \mathrm{~cm}$ の Meckel 摄室を認め,䕀室の楔状切除を行った.虫垂突起には炎症所見を認 めなかった。病理組織学的検査にて, 鄎室頂部付近に異所性の胃底腺組織を認めた. 穿 孔部は異所性胃粘膜近傍の回腸粘膜領域に存在し, 活動性消化性潰場の像を呈していた。 ギムザ染色にて，異所性胃粘膜から Helicobacter pylori は検出されなかった．本症例て は, 異所性胃粘膜から分泌される胃酸やペプシンによって近接する回腸粘膜に消化性潰 瘍を形成し，出血による筫血，さらには穿孔をきたしたと推測された．

索引用語：Meckel 数室, 潰瘍穿孔，異所性胃粘膜

緒言

Meckel 香室は卵黄腸管遺残症の82〜96\%を占め る゙. 生涯臨床症状を示さずに経過する場合が多いが, とくに小児期には時として種々の合併症をきた す ${ }^{3,6)}$.われわれは，異所性胃粘膜を伴う Meckel 想室 に消化性潰湟を形成し，穿孔をきたした1例を経験し たので報告する。

\section{症例}

症例：12歳, 男性.

主訴: 下腹部痛.

既往歴：6 歳時, 負血にて入院加療.

現病歴：1995年12月12日16時頃, 突然下腹部痛が出 現した，2 時間後に近医を受診し，内服薬処方を投与 されるも腹痛は軽快せず,同日 21 時に当院を受診した.

来院時現症：顔面はやや蒼白. 血圧110/70mmHg, 脈拍 $92 /$ 分·整. 脗下部を中心に圧痛を認めたが，腹膜 刺激症状はなく，腸雑音は正常であった。

来院時検查成績：白血球増多と鉄欠乏性貧血を認女 た. 生化学検査には異常を認めなかった（表 1).

腹部単純 X 線検查：両下腹部に少量の小腸ガス像

1997年 6 月24日受付 1997年 9 月11日採用
を認めたが，鏡面像形成や腹腔内遊離ガス像は認めな かった（図 1).

臨床経過：グリセリン浣腸にて血液の泿入をみない 黄色軟便を多量に排泄し，腹痛はやや軽減した。抗生 物質投与にて経過観察を行っていたところ腹痛は徐々 に増強し，幐下部から右下腹部にかけて筋性防御およ び Blumberg 徵候を認めるようになった。そのため, 急性虫垂炎を第一に疑い開腹手術を行った。

手術所見：右傍腹直筋切開にて開腹したところ,や や泿濁した淡血性腹水が貯留していた．回盲弁より約

\section{表 1 来院時血液生化学検查}

\begin{tabular}{lc|lr}
\hline $\mathrm{WBC}$ & $14.800 / \mu \mathrm{l}$ & $\mathrm{BUN}$ & $10.6 \mathrm{mg} / \mathrm{dl}$ \\
$\mathrm{RBC}$ & $478 \times 10^{4} / \mu \mathrm{l}$ & $\mathrm{Cr}$ & $0.4 \mathrm{mg} / \mathrm{dl}$ \\
$\mathrm{Hb}$ & $11.0 \mathrm{~g} / \mathrm{dl}$ & $\mathrm{TP}$ & $6.8 \mathrm{~g} / \mathrm{dl}$ \\
$\mathrm{Ht}$ & $33.3 \%$ & $\mathrm{GOT}$ & $20 \mathrm{IU} / l$ \\
$\mathrm{MCV}$ & $69.7 \mathrm{f}$ & $\mathrm{GPT}$ & $9 \mathrm{IU} / l$ \\
$\mathrm{MCH}$ & $23.0 \mathrm{pg}$ & $\mathrm{LDH}$ & $433 \mathrm{IU} / l$ \\
$\mathrm{MCHC}$ & $33.0 \mathrm{~g} / \mathrm{dl}$ & $\mathrm{ALP}$ & $914 \mathrm{IU} / l$ \\
$\mathrm{Plt}$ & $29.5 \times 10^{4} / \mu \mathrm{l}$ & $\gamma-\mathrm{GTP}$ & $9 \mathrm{IU} / l$ \\
$\mathrm{Na}$ & $139 \mathrm{mEq} / l$ & $\mathrm{CPK}$ & $123 \mathrm{IU} / l$ \\
$\mathrm{~K}$ & $4.0 \mathrm{mEq} / l$ & $\mathrm{~s} \cdot \mathrm{AMY}$ & $108 \mathrm{IU} / l$ \\
$\mathrm{Cl}$ & $105 \mathrm{mEq} / l$ & $\mathrm{Fe}$ & $35 \gamma / \mathrm{dl}$ \\
& & $\mathrm{CRP}$ & $0.0 \mathrm{mg} / \mathrm{dl}$ \\
\hline
\end{tabular}




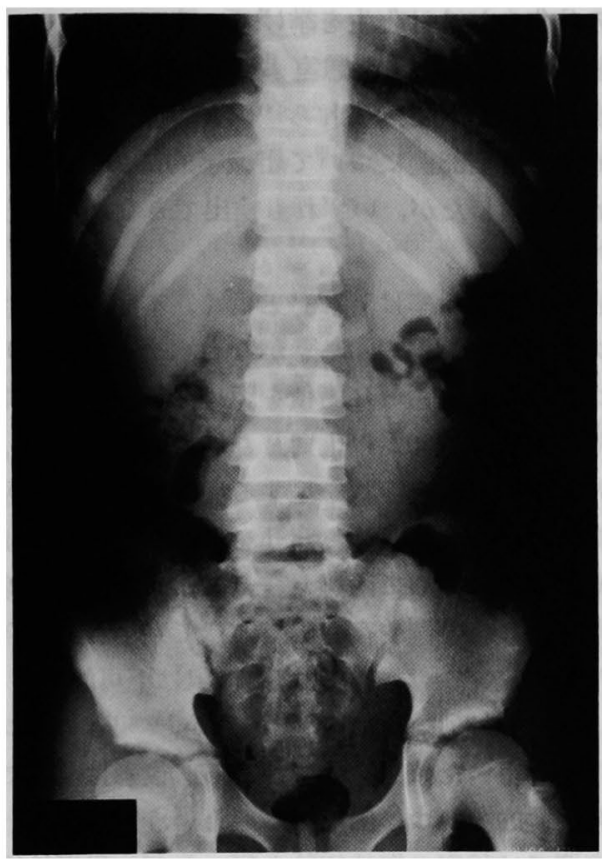

図 1 腹部単純 $\mathrm{X}$ 線：両下腹部に少量の小腸ガス像 を認める以外異常は認めない.

$90 \mathrm{~cm}$ 口側の腸間膜対側に, 穿孔を有する約 $6 \mathrm{~cm} \times 3 \mathrm{~cm}$ の Meckel 秘室を認めた（図 2a）. 腹腔内の検索では, 他に出血源と思われる病変はみられなかった。なお， 虫垂突起には炎症を認めなかった。憩室の楔状切除と 腹腔内洗浄・ドレナージを行って，手術を終えた。

切除標本所見：䕀室頂部より約 $2 \mathrm{~cm}$ 離れた部位に 消化性潰愓の穿孔を認めた（図 2b)。

病理組織学的所見：喤室頂部付近に限局性の胃底腺 組織を認めた(図 3a). 穿孔部は異所性胃粘膜近傍の回 腸粘膜領域に存在しており，側壁にフィブリンの沈着 を伴う活動性消化性潰場の所見を呈していた（図 3b). なおギムザ染色で, Helicobacter pylori は検出され なかった（図 4 ).

術後経過：術後は順調に経過し，17日目に軽快退院 した.

考 察

Meckel 党室は全剖検例の 1 ～2\%に存在するとい われ，消化管の先天奇形の中では最も頻度が高い2). 性 差は $2 \sim 3: 1$ と男性に多い3).

合併症は15〜33\%にみられ㣗年15), 男性に $2 \sim 3$ 倍の 頻度で発生する ${ }^{316)}$. 金田ら は, イレウス $35.1 \%$, 潰铬出血 $14.6 \%$, 腸重積 $14.5 \%$,
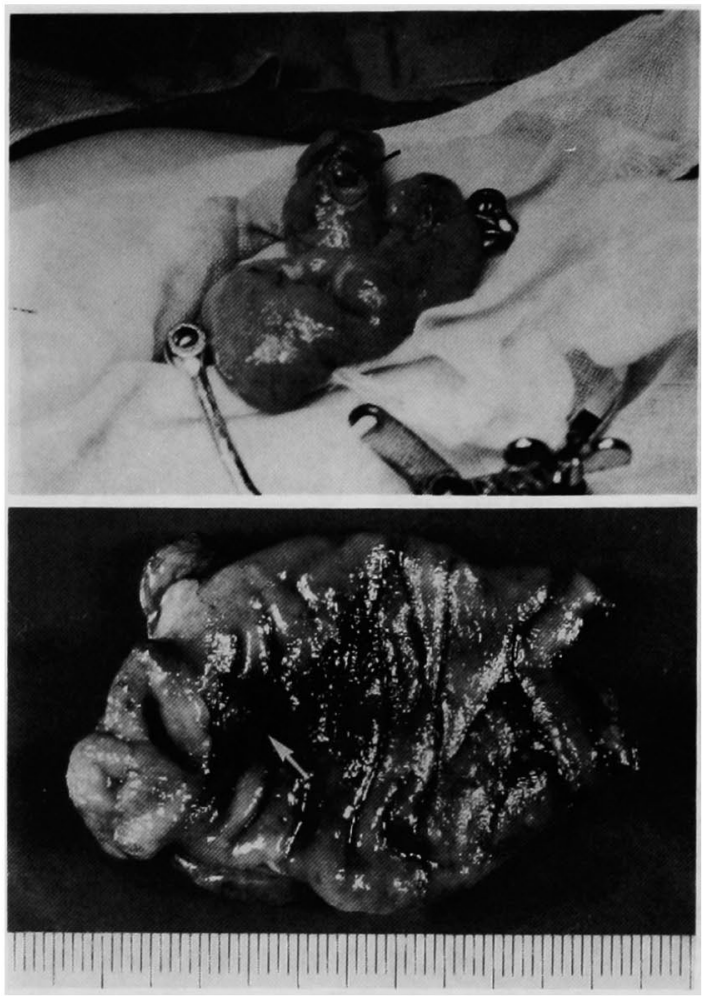

図 2 a) 手術所見：回盲弁より約 $90 \mathrm{~cm}$ 口側に穿孔 した Meckel 息室を認める（矢印：穿孔部).

b) 切除標本肉眼所見：秝室頂部近傍から約 $2 \mathrm{~cm}$ 離 れた部位に消化性潰場の穿孔を認める(矢印). $\frac{\mathbf{a}}{\mathrm{b}}$

顋室炎 $12.5 \%$, 穿孔 $9.4 \%$ \%゙であった。一方欧米の報 告では, 潰瘍出血が30.9\%〜 53.7\% と最も多い7 10). 異所性胃粘膜と出血との関係は深く, 出血をきたした 症例の中で胃粘膜の存在は，小児の報告では $97 \sim 100 \%^{91111}$, 成人を含む報告では59〜62\% ${ }^{3 / 12)}$ あった. 出血の機序としては, 異所胃粘膜から分泌さ れる塩酸やペプシンにより周囲の回腸粘膜に消化性潰 瘍が生じるためと推定されている(3). 本症例において も，淡血性腹水と慢性鉄欠乏性筫血を認めたことより， Meckel 敗室の消化性潰瘍からの持続性出血があった ものと推測された。

異所性組織の迷入頻度は15〜 70\%で316), Yamaguchi ら ${ }^{31}$ は胃粘膜が $62.4 \%$, 脺組織が $16.1 \%$, 胃粘膜と膵組 織の同時迷入 $5.4^{\mathrm{o}}{ }_{\mathrm{o}}$ と報告し, Benson ${ }^{13}$ は胃粘膜が $85.5^{\circ} \%$, 脺組織 $33.2{ }^{\circ}{ }_{0}$, 胃粘膜と脺組織の同時迷入 $9.6 \%$ としている. 異所性胃粘膜の成因については,い 


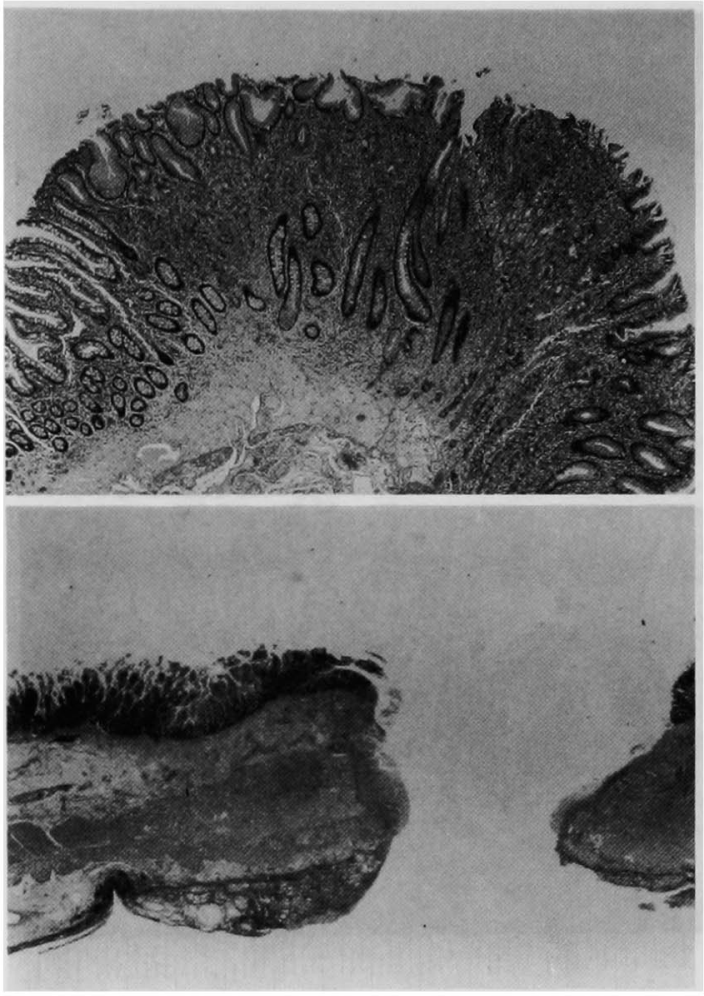

図 3 病理組織学的所見：a) 䈍室頂部 (HE 染色, $x$ 40)：限局性の胃底腺組織を認める。 b) 穿孔部(HE 染色×4）：回腸粘膜領域にありフィブリン沈着を 伴った肉芽形成を認める。

$$
\frac{a}{b}
$$

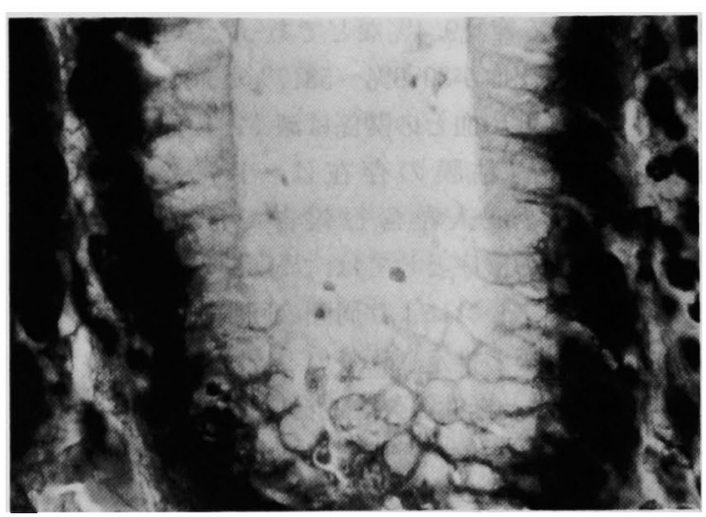

図 4 病理組織学的所見(ギムザ染色, ×1,000)： Helicobacter pylori は検出されなかった。

まだ定説がない，Gray ら”は，その成因として胎児期 における胃組織の，(1) 転位，(2) 浸潤性遊走，(3) 腸
粘膜の分化もしくは化生を挙げている。

本症例では, Meckel 憩室より Helicobacter pylori を検出しえなかった。.Fich ら ${ }^{141}$ は異所性胃粘膜を有す る Meckel 秘室23例について組織学的に Helicobacter pyloriを検索したが，いずれも検出できなかったと報 告している.

本症の術前診断率は $5.7 \%{ }^{3)}$ と低く，本症例も急性虫 垂炎の診断のもとに開腹術がなされた。 ${ }^{99 \mathrm{~m}} \mathrm{TcO}_{4}^{-}$ス キャンでは胃底腺領域に集積を認め，異所性胃粘膜迷 入例での確診率は $90 \%$ 以上 ${ }^{15)}$ とれている。しかし,自 験例のように腹膜炎症状を呈する症例には通常核医学 的検查を施行しないため，穿孔をきたした Meckel 息 室の術前診断は極めて困難と言える．また，胃底腺組 織が存在しない症例や存在したとしても小さい場合に

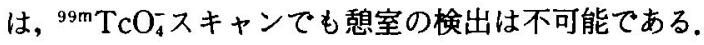

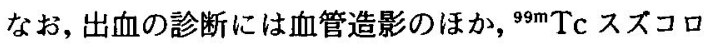
イドなどを用いた核医学検査がある，後者は前者に比 べて非侵擎的でかつ検出能も高いという'

本症例では想室の楔状切除を行ったが，異所性組織 の取り残し ${ }^{171}$ や㲘室の癌化 ${ }^{181}$ の可能性があることから 䕀室を含む小腸切除を推孚するものもある.最近では， 術前に本症と診断しえた症例に対し, minimally inva sive surgery としての腹腔鏡下賏室切除も行われてい $3^{19)}$.

今回の症例のように, 慢性負血を伴った腹痛の場合, 患者の状態の許す限り, Meckel 数室の存在も念頭に 置いて検查を進めるべきであると考える.

\section{結語}

潰愓穿孔をきたした，異所性胃粘膜を伴う Meckel 賏室の 1 例を経験したので, 若干の文献的考察を加え て報告した。

\section{文献}

1) Gray SW: Heterotopic gastric mucosa in other organs: Embriology for Surgeons. WB Saunders Co., Philadelphia, 1972, p123-124

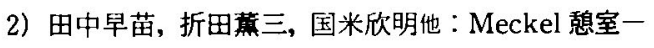
本邦報告例444例の統計的観察を中心に一. 外科診 療 $13: 818-826,1971$

3) Yamaguchi M, Takeuchi S, Awazu S: Meckel's diverticulum: Investigation of 600 patients in Japanese literature. Am J Surg 136: 247249,1978

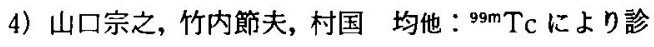
断し得た Meckel 㓤室の1例と本邦報告例580列 
の統計的観察. 臨外 $31: 1647-1651,1976$

5）金田 真, 山本敏雄, 矢野隆嗣他：Meckel 想室の Mesodiverticular vascular bandにより皎㹉性イ レウスを来した 1 例. 外科診療 31 ：300-304, 1989

6) Macky WC, Dineen P: A fifty year experience with Meckel's diverticulum. Surg Gynecol Obstet $156: 56-64,1983$

7) Weinstein EC, Cain JC, ReMine WH : Meckel' s diverticulum : 55 years of clinical and surgical experience. JAMA $182: 251-253,1962$

8) Williams RS: Management of Meckel's diverticulum. Br J Surg 68: 447-480. 1981

9) Rutherford RB, Akers DR: Meckel's diverticulum: A review of 148 pediatric patients, with special reference to the pattern of bleeding and to mesodiverticular vascular bands. Surgery $59: 618-626,1966$

10) Gross RE : The surgery of infancy and childhood. WB Saunders, Philadelphia \& London, 1960, p211-220

11) Vane DW, West KW, Grosfeld JL: Vitelline duct anomalies: Experience with 217 childhood cases. Arch Surg 1:2: 542-547, 1987

12) Moore $T$, Johnsotn AOB: Complications of
Meckel's diverticulum. Br J Surg $63: 453-454$, 1976

13) Benson CD: Surgical implication of Meckel's diverticulum. Pediatric Surgery, ed3. Year Book Medical Publishers, Chicago, 1979, p955960

14) FichA, Talley NJ, Shorter RG, et al: Does Helicobacter pylori colonize the gastic mucosa of Meckel's diveticulum? Mayo Clin Proc 65 : 187-191, 1990

15) Sfakianakis GN, Haase GM: Abdominal scintigraphy for ectopic gastric mucosa: A Retrospective analysis of 143 studies. AJR 138: $7-12,1982$

16）祖母井努, 佐藤友保, 衣笠信行他：術前診断が可能 であったィッケル㲘室の1例. 臨床画像 $10: 113$ $-116,1994$

17）杉原登司夫, 佐々木宏之, 竹内絢子他：高龄男性に みとめられた Meckel 悡室炎の 1 例. 島根医 6: $69-71,1979$

18）稲葉 裹, 垣花昌彦, 畠山 茂: Meckel 惒室癌の 1 例. 外科診療 $1: 87-92,1959$

19）谷口勝俊：メッケル賏室に対する縮小手術。日医 新報 $3712: 37-40,1995$

\title{
A CASE OF MECKEL'S DIVERTICULUM CAUSING PERFOTATION OF PEPTIC ULCER
}

\author{
Hidemaro YOSHIBA, Takahiro KINOSHITA and Katsuya MORITA \\ Department of Surgery, Johana Kosei Hospital \\ Kenji OMURA \\ Department of Surgery I, Kanazawa University
}

A 12-year-old male boy, whe had been suffered from anemia at the age of 6 , was admitted to the hospital because of lower abdominal pain. His blood chemistry showed iron-deficiency anemia. After admission the pain was intensified and peritoneal stimulating sign developed. He was diagnosed as having acute appendicitis and operated on. At the surgery. slight-blood a scites was detected and perforated Meckel's diverticulum $6 \mathrm{~cm} \times 3 \mathrm{~cm}$, in size was revealed at antimesenteric side of the ileum which was $90 \mathrm{~cm}$ from the ileocecal valve. A wedge resection of the diverticulum was carried out. The appendix was intact. Pathological examination revealed that there we ectopic gastric parietal gland at the apex of the diverticulum. The perforation was in the area of ileal mucosa near the ectopic gastric mucosa. It was active peptic ulcer. Helocobacter pylori was not found in the ectopic mucosa with May-Giemsa staining. In this case, gastric acid and/or pepsin rescreted from the ectopic mucosa should cause peptic ulcer in the ileal mucosa, and then hemorrhage and perforation developed. 